\title{
Low-Tech Coconut Shell Activated Charcoal Production
}

\author{
Ami Cobb \\ Senior, Department of Civil Engineering \\ Santa Clara University \\ Santa Clara, CA 95053 \\ AmiCobb@gmail.com \\ Mikell Warms \\ Senior, Department of Civil Engineering \\ Santa Clara University \\ Santa Clara, CA 95053 \\ Mikell.Warms@gmail.com \\ Dr. Edwin P. Maurer \\ Associate Professor, Department of Civil Engineering \\ Santa Clara University \\ Santa Clara, CA 95053 \\ EMaurer@scu.edu \\ Dr. Steven Chiesa \\ Associate Professor, Department of Civil Engineering \\ Santa Clara University \\ Santa Clara, CA 95053 \\ SChiesa@scu.edu
}

Abstract - Water treatment technologies in the developing world typically focus on removing two types of impurities from water sources: suspended solids and microbial pathogens. However, as industrialization and high-input agriculture has expanded into the developing world, chemical impurities such as pesticides, herbicides, and fertilizers have found their way into drinking water supplies and have been linked to severe health-related issues. Activated carbon has the capacity to remove these problematic chemicals from water sources. A simple, inexpensive, and effective activated carbon production process using local agricultural waste byproducts was assessed for the community of Bluefields, Nicaragua. Coconut shell charcoal was produced on site, and various chemical activation techniques were investigated. The adsorption capacity of three separate chemically activated coconut shell charcoals was analyzed, with sodium chloride-common table salt—being the most efficient and cost effective activating agent.

Index Terms - Activated carbon, water quality treatment, low-tech, chemical activation

\section{INTRODUCTION}

Addressing the deterioration of water quality in developing countries, where an estimated one billion people lack access to potable quality water, ${ }^{1}$ is a primary motivating factor for many community development efforts and is a key component of the Millennium Development Goals. ${ }^{2}$ Water quality improvements inspired by these goals are currently focused on reducing diarrheal illnesses and, hence, are focused on biological contamination and related pathogen removal. ${ }^{3}$ These water quality improvements are commonly achieved by point of use (POU) treatment 
systems in developing countries. However, as industrialization, including high-input agriculture, has expanded into less developed areas around the world, people must contend with additional sources of contamination due to surface runoff and deep percolation containing pesticide, herbicide, and fertilizer residues. ${ }^{4}$ Such problems are exacerbated by poor sanitation, lack of education, and largely unenforced regulations. This has significantly increased the need for a higher level of treatment for drinking water. ${ }^{5}$ Even communities that employ centralized municipal treatment facilities often lack the ability and resources to quantify and remove the ever-increasing diversity of contaminants and are forced to provide less than desirable levels of treatment.

Implementing POU treatment systems and devices can reduce the cost and time of modifying current municipal treatment facilities ${ }^{6}$ and can offer viable, low-cost alternatives for those communities without centralized municipal systems or potable water distribution infrastructures. POU treatment systems and devices, originally developed to deal with suspended particulate materials and microbial pathogens, must now contend with the chemical wastes from modern agribusiness practices. ${ }^{7}$ In 2008, the World Bank estimated that 355,000 people worldwide die each year from unintentional pesticide poisoning. Two-thirds of these deaths occur in developing countries. $^{8}$

Depending on the type of pesticide or herbicide present and the extent of exposure, these chemicals can cause mild headaches, flu-like symptoms, skin rashes, blurred vision, and in severe chronic exposure cases, paralysis, blindness, sterility, and even death. ${ }^{9}$ POU water treatment alternatives have been introduced and successfully implemented within impoverished areas, primarily where nonprofit organizations have taken greater notice and where governments have emphasized the need for improved water quality. ${ }^{10}$ Common methods include solar disinfection (SODIS), filtration with ceramic media, chlorination, and bio-sand filtration (BSF). ${ }^{11}$ Despite the efficiency of these systems at removing biological contaminants, they lack the ability to effectively remove dissolved organic impurities such as pesticides. Additional treatment is required in areas where these chemical contaminants are prevalent. This study was initiated to identify an inexpensive option for those communities that lack the means to remove such dissolved organic chemical impurities from their drinking water. After researching all the possible POU treatment options available, our proposed solution was to use local agricultural waste byproducts to produce a low-tech, chemically activated carbon that could be used in conjunction with existing POU technologies or as a stand-alone treatment option. While activated carbon filtration has been used in municipal treatment facilities and POU applications in the developed world, it can also be used to mitigate the critical health-related concerns due to pesticide contamination and consumption in the developing world.

\section{STUDY AREA}

To determine if chemically activated carbon could be produced in the developing world, this project started with a field visit to Bluefields, Nicaragua. Bluefields is an isolated city situated along the Caribbean coast of Nicaragua (Figure 1) and is the administrative capital of the Region Autonoma del Atlantic Sur (RAAS). With a growing population of about 50,000, the deteriorating sanitation and potable water scarcity is quickly becoming a dangerous situation. Most people in the area depend on hand-dug wells or streams that are often contaminated. A long dry season further exacerbates these issues. ${ }^{12}$ A significant factor in choosing Bluefields as our test site is that it is the base for blueEnergy, a non-profit organization collaborating with the 
School of Engineering at Santa Clara University. This non-governmental agency (NGO) has promoted the use of individual bio-sand filters to improve drinking water quality. blueEnergy encourages student participation in their efforts towards improving the lives of marginalized communities in and around Bluefields. The NGO provided technical and logistical support for our investigation. ${ }^{13}$

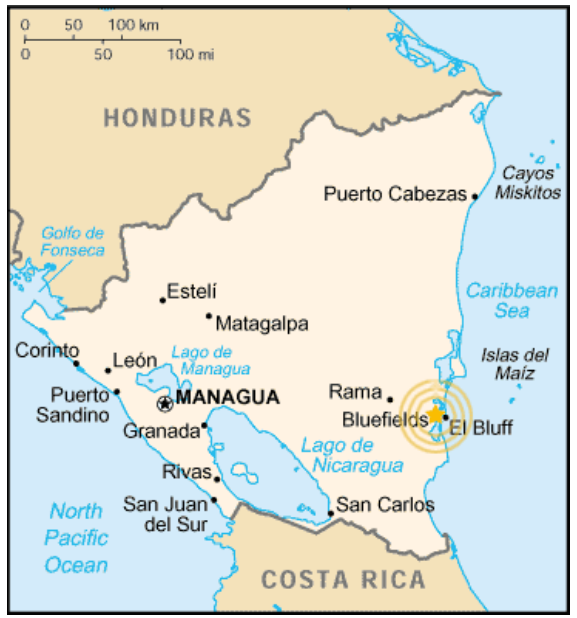

FIGURE 1

LOCATION OF BLUEFIELDS, NICARAGUA ${ }^{14}$

During the site visit to Bluefields, many of the locals were interviewed about their water quality concerns and, in particular, their use of bio-sand filters. While blueEnergy has installed filters around the city, it was unclear if these filters were used properly or whether these recentlyintroduced POU systems had high rates of acceptance. One family mentioned that despite owning a bio-sand filter, their children still had to drink bottled water in order to avoid sickness. This case suggested that (1) families suffering with this issue were not using the filter correctly, (2) the filter itself was not functioning properly due to a malfunction, (3) the filter was functioning properly but still not providing adequate treatment of the bacteria or pesticides in the water supply, or (4) the children were getting sick for other reasons and the parents attributed their sickness to contaminated water. The first two possibilities were beyond the scope of this study; cultural acceptance and education for these treatment options can take generations to instill. Also, there are many effective ways of providing a secondary treatment for removing pathogens that may have passed the primary bio-sand filtration, such as chlorine tablets or solar disinfection (SODIS). Assuming the fourth possibility to be erroneo?us, the need to produce a filter media that could remove physical contaminants that bio-sand filters (and other POU systems) failed to remove was evident. While keeping the local residents' tendencies and concerns in mind, one of the main goals was to focus on a system capable of having a high rate of acceptance. The strongest message that was taken away through the site visit was that only a simple, one-step filtration system such as a bio-sand filter would realistically be accepted and properly used; the locals were not likely to purify their drinking water using a complicated, timeconsuming, multi-step process. The site visit provided the type of feedback needed to truly grasp the economic, environmental, and social constraints that should be considered in the design process of any upgraded or retrofitted treatment system. Since the local communities are unlikely 
to accept activated charcoal as a separate, secondary treatment system, the chosen strategy was to evaluate retrofitting the current bio-sand filter design with a layer of activated charcoal.

\section{METHODS}

To design an activated charcoal system for removing pesticide contamination, a solution that could be used in conjunction with existing POU systems in our study region (and globally) was necessary. In addition, a sufficient source of carbon and an activation technique that would be appropriate for the local conditions and resources was needed. The production and design alternatives were tested qualitatively in the field and quantitatively in a laboratory at Santa Clara University to assess performance and feasibility.

\section{Carbon Source}

For the carbon source, it was economically important to use a readily available agricultural waste byproduct. In Bluefields and the surrounding rural towns, there were several alternatives to choose from including sugar cane husks, corncobs, and coconut shells and husks. Since coconut is commonly used throughout the world as an activated carbon source material, ${ }^{15}$ testing was initiated using both coconut shells and coconut husks.

Although coconut husks can be carbonized much more efficiently than coconut shells due to their flammability, utilizing the husks as a filter medium proved unsuccessful due to fine charcoal residues leaching into the water during filtration. The husk-generated carbon was not very durable and physically broke down in the treatment system very quickly. Using the more durable coconut shell-based carbon eliminated this issue. However, coconut husks proved to be a useful combustion medium to improve the carbonization of the coconut shells. The remaining carbonized coconut husks could be pulverized into charcoal briquettes with a binder - cassava root, aloe, and banana are often used - and subsequently used for cooking purposes to decrease waste as well as to decrease the need for local residents to cut down trees for charcoal production. ${ }^{16}$

\section{Charcoal Production}

Charcoal can be produced almost anywhere in the world. Wood is the material most often used to produce charcoal; one of many causes for the rapid rate of global deforestation. ${ }^{17}$ Instead of trees, many agricultural waste byproducts are used to replace wood as the carbon source. Activated carbon can be developed from many sources, such as cherry stones, macadamia nut shells, and palm husks. ${ }^{18}$ The source and quality of the carbon may play a role in the quality and consistency of activated carbon produced, but to reduce ecological impact, local agricultural waste byproducts can be used as a replacement in the activated carbon production process.

The charcoal production method employed in Bluefields involved a modified pyrolysis technique using an empty 55-gallon steel oil drum. The process was quite simple and can be adapted globally. The agricultural waste byproducts were placed into the oil drum and lit from the bottom. Once the materials inside the drum were fully ignited and the water in the carbon source had evaporated, the drum was sealed to initiate the anoxic combustion process. Over the next two to three hours, the material was successfully carbonized and charcoal was formed. ${ }^{19}$ Once the charcoal was completed, it was sorted by visual inspection to find material that had been thoroughly carbonized. Shells that retained a natural brown color and that were difficult to break by hand were excluded. Any material that had not been completely carbonized was saved for the following batch. The oil drum method produced approximately $5 \mathrm{~kg}$ of charcoal material 
per operating cycle when the drum was completely filled with the selected carbon source and combustion medium.

\section{Activation Process}

Activated carbon is produced in most developed areas around the world. It is one of the strongest adsorbents known and has surface areas that can reach $1500 \mathrm{~m}^{2} / \mathrm{g}$. The highly porous carbon is produced commercially in the developed world through a traditional steam activation process. ${ }^{20}$ Unfortunately, such a high quality activated carbon requires pyrolysis temperatures of approximately 800 to $1000^{\circ} \mathrm{C}$. This temperature range is infeasible using the technologies readily available in the developing world on a small scale. Alternatively, activated carbon can be produced via chemical activation of charcoal. This process involves soaking charcoal in a strong dehydrating agent such as calcium chloride $\left(\mathrm{CaCl}_{2}\right)$ or zinc chloride $\left(\mathrm{ZnCl}_{2}\right)$ after it has been carbonized at temperatures ranging from 500 to $800^{\circ} \mathrm{C} .{ }^{21}$ Since steam activation is highly improbable, dangerous, and prohibitively expensive for small-scale systems in the developing world, this investigation focused on exploring inexpensive ways to chemically activate charcoal to form activated carbon.

After charcoal was produced as described in the previous section, the materials were broken into smaller pieces without crushing them down to fine powder. Although powder has a much higher surface area per unit mass than the granular carbon (and thus a higher removal capacity), it is difficult for bio-sand filters to effectively separate the powdered carbon from the treated water. The pieces of the charcoal should be approximately 1.0 to $5.0 \mathrm{~mm}$ in size, corresponding to standard sieves 4-16. Once this step was completed, the pieces were soaked in a $25 \%$ solution of $\mathrm{CaCl}_{2}$ or $\mathrm{ZnCl}_{2}$ for 24 hours. They were then rinsed thoroughly and either allowed to dry in the sun or placed in an oven at approximately $100^{\circ} \mathrm{C} .^{22}$

\section{Testing of Activated Charcoal}

While in Bluefields, the locally-produced activated carbon was tested by means of a qualitative, visual colorimetric method using a common dye indicator (methyl orange) as a proxy chemical for pesticides and herbicides. Activated carbon samples produced in Nicaragua were taken to Santa Clara University to be tested further. Two techniques were used to assess adsorption capacity. The first was a semi-quantitative colorimetric method using atrazine, a common herbicide used globally. The second was a more quantitative colorimetric laboratory method employing a spectrophotometer and methyl orange.

\section{Qualitative Method}

Without proper instrumentation in Bluefields, only qualitative testing of chemically activated carbon was feasible. Methyl orange, a highly soluble organic dye, was used to preliminarily assess whether the chemical activation had been successful. A dilute methyl orange solution was made to test the charcoal once it had been processed with the different chemicals mentioned above. Approximately one gram of activated charcoal was placed into the test solution and 10 minutes were allowed for adsorption to take place before the treated solution was passed through a common coffee filter. The observed decrease in the color intensity of the methyl orange solution following this final filtration step was an indication that the charcoal had been successfully activated. This testing approach demonstrated that methyl orange (or other common organic dyes) could potentially provide a visual quality control technique for future activated carbon production. 


\section{Semi-Quantitative Method}

Upon returning to Santa Clara University from Bluefields, a Hach ${ }^{\mathrm{TM}}$ Pocket Colorimeter II was used to test water samples with varying atrazine concentrations. Because of its extensive global use, atrazine was used as the proof-of-concept test material for pesticide/herbicide removal by the chemically activated carbon. The U.S. Environmental Protection Agency has set the maximum contaminant level (MCL) for Atrazine at 3 ppb. ${ }^{23}$ This test is performed by adding samples, standards, and reagents to cuvettes coated with antibodies specific for atrazine. Once the color intensity of the atrazine/reagent product has been developed, the resulting color intensity and atrazine concentration are found using the colorimeter. This particular colorimeter can only test for 3 specific ranges of atrazine: (1) $>3.0 \mathrm{ppb},(2)<0.5 \mathrm{ppb}$, and (3) between 0.5 to $3.0 \mathrm{ppb}$. Tests were conducted in accordance with the Pocket Colorimeter II instruction manual provided by the $\mathrm{Hach}^{\mathrm{TM}}$ Company, Loveland $\mathrm{CO} .{ }^{24}$ Three different chemically activated carbons were tested: one activated using a $25 \%$ calcium chloride solution, one activated using $50 \%$ sodium chloride solution, and a third activated using $25 \%$ sodium chloride solution. The chemically activated carbon samples were placed into separate beakers each containing either 5 ppb or $10 \mathrm{ppb}$ stock atrazine solutions. Two minutes were allowed for the adsorption reactions to occur. This two minute time period was based upon the expected contact time in an actual biosand filter. Carbon materials were then filtered using glass fiber filters and the solutions were tested for atrazine.

\section{Quantitative Method}

Since the $\mathrm{Hach}^{\mathrm{TM}}$ colorimeter only provided semi-quantitative results, an additional quantitative assessment of the adsorption capacity and useful life of the chemically activated carbon was performed using methyl orange as the test material. Concentration levels were measured with a Milton Roy Model 20 spectrophotometer. A $425 \mathrm{~nm}$ wavelength was used to measure the color intensity for the yellowish solutions produced in the experiments. A linear relationship between concentration and absorbance was observed when using known concentrations of methyl orange and the corresponding absorbance readings from the spectrophotometer. ${ }^{25}$ This calibration curve was used to determine the equilibrium concentrations of methyl orange during the batch adsorption experiments. The goal of this experiment was to develop adsorption isotherms for the tested activated carbon. Five beakers with $0.5 \mathrm{~L}$ of a $20 \mathrm{mg} / \mathrm{L}$ methyl orange stock solution were combined with 1, 2, 3, 5, and 10 grams of each type of activated carbon. A blank containing deionized water with added activated carbon was used to account and correct for any color imparted to the solution phase by the activated carbon alone. The activated carbon samples tested consisted of granular particles passing a number 10 standard sieve $(2.0 \mathrm{~mm})$ and retaining on a number 40 standard sieve $(0.42 \mathrm{~mm})$. After allowing 24 hours for complete adsorption, the absorbance of the filtered test solutions was measured to determine the amount of methyl orange remaining in solution. The absorbance of the blank was subtracted from the absorbance of the five test solutions.

\section{RESUlTS \& DISCUSSION}

\section{On-site Qualitative Results}

Although $\mathrm{CaCl}_{2}$ and $\mathrm{ZnCl}_{2}$ have been proven to successfully produce activated carbon from charcoal, ${ }^{26}$ they are difficult to obtain and are prohibitively expensive in most regions of the 
developing world. An inexpensive chemical that could effectively activate charcoal would be necessary if the activated carbon production was going to be feasible. Since $\mathrm{CaCl}_{2}$ is a chloride salt, we performed an experiment with another more readily available chloride salt, $\mathrm{NaCl}$. Since a $25 \%$ solution of $\mathrm{CaCl}_{2}$ has been shown to successfully create activated carbon from charcoal, a $50 \%$ solution of $\mathrm{NaCl}$ was tested to provide an equal concentration of positive and negative charge in solution. As evidenced in Figure 2 below, the charcoal treated with the $50 \% \mathrm{NaCl}$ solution produced positive results. To potentially reduce costs even further, charcoal treated with a $25 \%$ solution of $\mathrm{NaCl}$ was tested as well and produced similar results. A blank coconut shell charcoal without any chemical activation step was also tested to ensure that the (non-activated) charcoal was not providing any adsorption. No color change or associated methyl orange removal was observed during this experiment. The positive qualitative results from the tests in Bluefields, given the obvious color change of the methyl orange solution, suggested that common table salt could be used as a replacement for the normal chemical activation agents. However, given the limited instrumentation available, there was no way to quantify and compare the adsorption capacities.

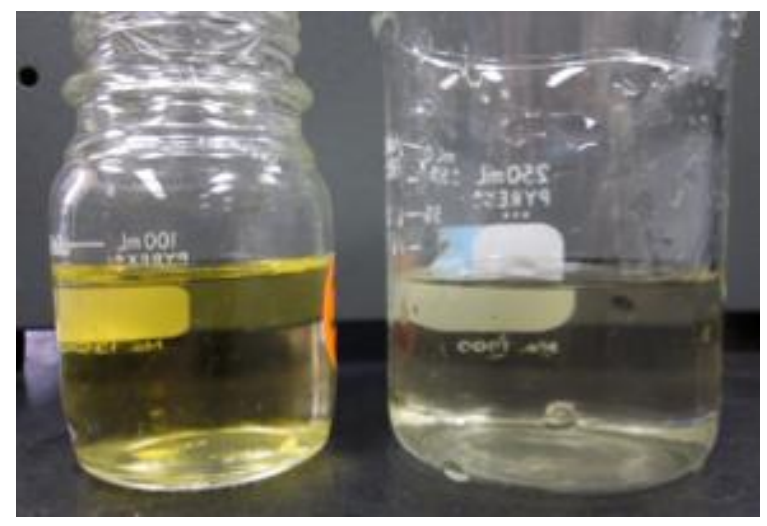

FIGURE 2

Qualitative EXPERIMENTATION: Before AND AFTER ACTIVATED CharCOAL TREATMENT

\section{Semi-quantitative Laboratory Results}

Upon return to Santa Clara University, a more quantitative approach was developed to determine the adsorption capacity and useful life of the chemically activated carbon that had been produced in Nicaragua. Approximately $5 \mathrm{~kg}$ of carbonized coconut shells produced in Bluefields was evaluated in the laboratory.

The approximate reduction in atrazine after treating the stock solutions with the three different types of chemically activated carbons $\left(25 \% \mathrm{CaCl}_{2}, 50 \% \mathrm{NaCl}, 25 \% \mathrm{NaCl}\right)$ was quantified using the $\mathrm{Hach}^{\mathrm{TM}}$ colorimeter. For all three cases, the Hach ${ }^{\mathrm{TM}}$ colorimeter determined the residual atrazine level to be between 0.5 and $3.0 \mathrm{ppb}$. This represented decreases of at least $40 \%$ and $70 \%$ for the 5 and $10 \mathrm{ppb}$ atrazine test stock solutions, respectively. The experiment demonstrated that the chemically activated carbon could successfully reduce the concentrations 
of chemical impurities such as pesticides and herbicides to below the nationally accepted potable water quality maximum contaminant levels in the United States. However, the semi-quantitative testing equipment available had insufficient precision to produce detailed adsorption isotherms. Additional experiments were performed with methyl orange to better quantify the adsorption capacity of the activated charcoal.

\section{Quantitative Laboratory Results}

Colorimetry was used to develop adsorption isotherms, a common method used for determining the performance of activated carbon. As detailed earlier, a linear calibration curve for methyl orange was developed using a set of standard solutions. The linear regression equation determined was $\mathrm{A}=0.0626^{*} \mathrm{C}$ (where $\mathrm{A}=$ Absorbance and $\mathrm{C}=$ Concentration of Methyl Orange in $\mathrm{mg} / \mathrm{L}$ ), with an associated $\mathrm{R}^{2}$ value of 0.99904 .

Methyl orange was chosen as an appropriate proxy chemical to test the adsorption capacity of activated carbon for several reasons. First, a linear relationship between concentration and absorbance could be easily developed using a spectrophotometer. Second, methyl orange is a very conservative proxy in that it is highly soluble in comparison to many organic pesticides and herbicides. The water solubility of methyl orange is near $200 \mathrm{mg} / \mathrm{L}$ at standard temperature and pressure. Activated carbon adsorbs relatively insoluble organic materials much more readily than soluble organics like methyl orange. Thus, activated carbon should have a higher adsorptive capacity for pesticides and herbicides than it would for methyl orange, leading to the conclusion that the developed isotherms should be a very conservative estimate of adsorption capacity. Adsorption isotherm results are provided in Figure 3 below.

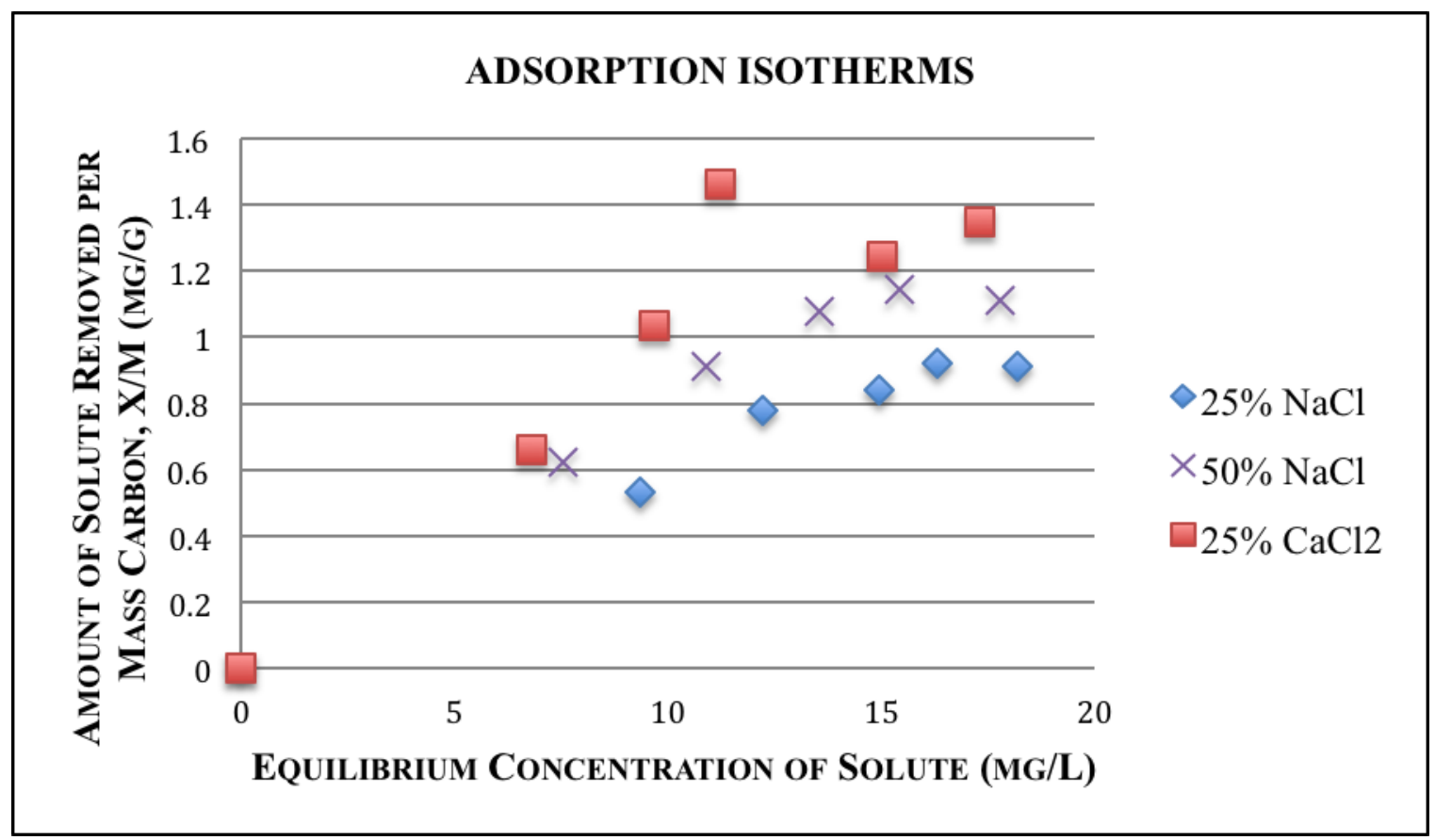

FIGURE 3 


\section{ADSORPTION ISOTHERMS FOR CHEMICALLY ACTIVATED CHARCOALS AND NON-ACTIVATED COCONUT SHELL CHARCOAL}

Figure 3 shows that the $25 \% \mathrm{CaCl}_{2}$ solution proved to be only slightly more effective than both sodium chloride trials. When compared to an identically tested steam-activated carbon manufactured in the United States (Siemens Inc.), the chemically activated carbon had approximately one-sixth the adsorptive capacity recorded for methyl orange. Given that it is nearly impossible to produce steam activated carbon without large amounts of energy and equipment, this is an encouraging result.

\section{Implementation}

The ultimate goal of this research project was to produce a chemically activated charcoal that could be effectively used in conjunction with existing POU treatment options without increasing overall system operational complexity. Since individual bio-sand filters are the most common treatment option currently used in Bluefields, a laboratory scale test system was built to mimic the functionality of its field-based counterpart. The laboratory scale system was designed around specifications used by blueEnergy and originally produced by the Centre for Affordable Water Sanitation \& Technology (CAWST). ${ }^{27}$ Figure 4A below shows the CAWST bio-sand filter design. In retrofitting the existing bio-sand filters, two major performance and related design criteria were identified as being critical. First, the activated carbon granular media and traditional silica sand media would need to work effectively together. Second, the silica sand media used in the traditional bio-sand filter would need to remove the any fine activated carbon residue that otherwise might be carried away with the treated water.

The first performance criterion could be addressed in several possible ways. If the activated charcoal were placed in a separate column connected directly to the effluent port of the bio-sand filter, then both systems would work independently of each other. However, this method provides no capacity for removing post-treatment activated charcoal residues. Attempts to remove this charcoal residue by filtration with either cloth fabric or filter paper proved to be too time consuming and cumbersome for a high degree of acceptance. A second option considered was placing the activated charcoal in a small contact column holding tank or fabric pouch atop the diffuser plate above the silica sand layer of the bio-sand filter. This approach could easily be implemented to satisfy both performance criteria, but would require significant additional cost. The simplest way to add an activated charcoal contact zone into an existing bio-sand filter without adding any new materials was to replace the top 4 to 5 inches of silica sand in the biosand filter with activated carbon (1 to $2 \mathrm{~kg}$ added dry carbon mass), right below the diffuser plate. This option is portrayed in Figure 4B below. The biologically active layer in the bio-sand filter, or schmutzdecke, should be unaffected so long as it is completely submerged under water at all times. The second performance criterion is taken care of as well, since the bio-sand filter is able to filter out any fine residues created during activated charcoal contact. The only drawback to this solution is that the activated carbon will need to be replaced from time to time depending on the influent concentration of target impurities in the source water. The useful life of $1 \mathrm{~kg}$ of charcoal activated with a $50 \% \mathrm{NaCl}$ solution is 40 days. This calculation assumes a highly conservative influent water concentration of $100 \mathrm{ppb}(0.1 \mathrm{mg} / \mathrm{L})$ at a consumption rate of 20 L/day at $75 \%$ carbon efficiency. The sand may also need to be flushed more frequently to make up for the slight loss in the depth of silica sand. 
For those local residents who don't own bio-sand filters or do not have access to one, a simple plastic bottle sand filter with a layer of activated charcoal atop the silica can be used to provide POU treatment. The activated charcoal can be wrapped in a cloth sleeve to facilitate replacement. It is recommended that the end user either provides chlorination or employs a SODIS-based approach to reduce pathogens in the water. The plastic bottle filter is shown in Figure 4C.

A)

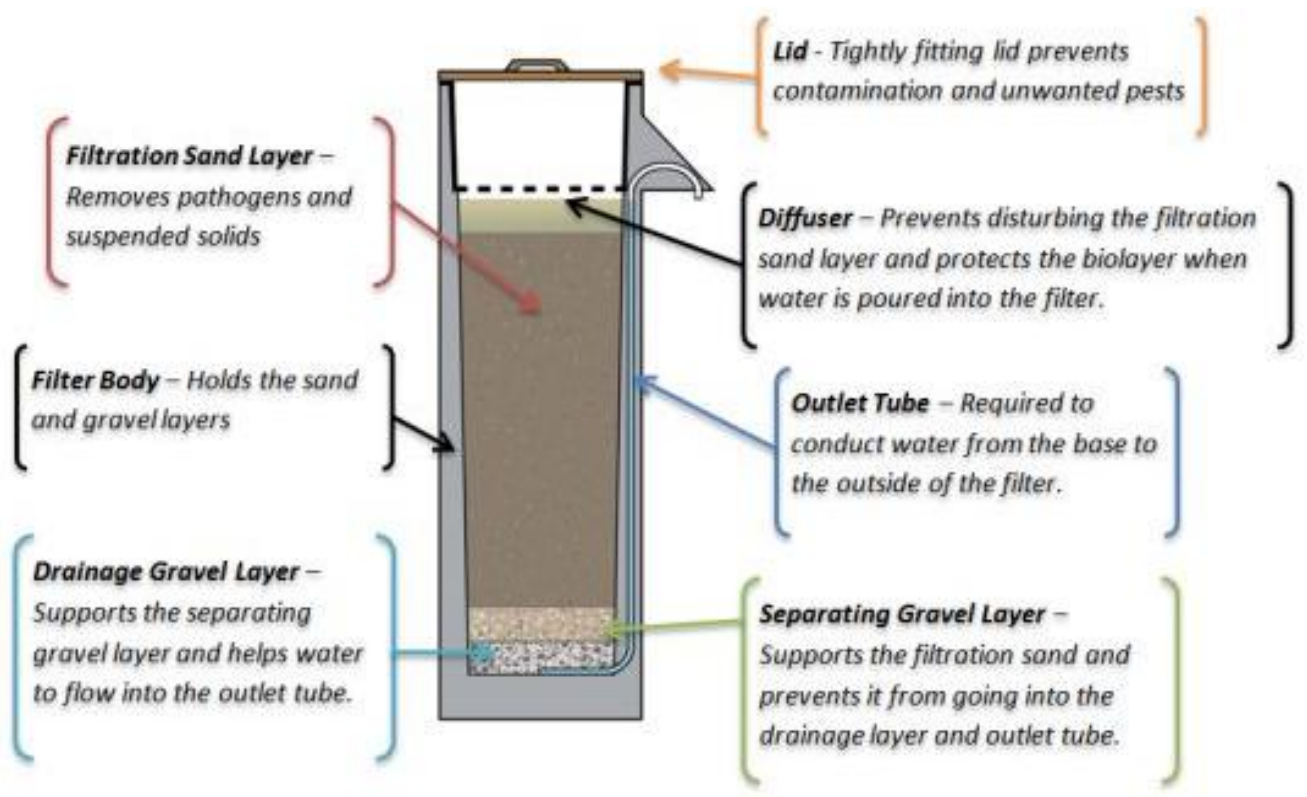

B)

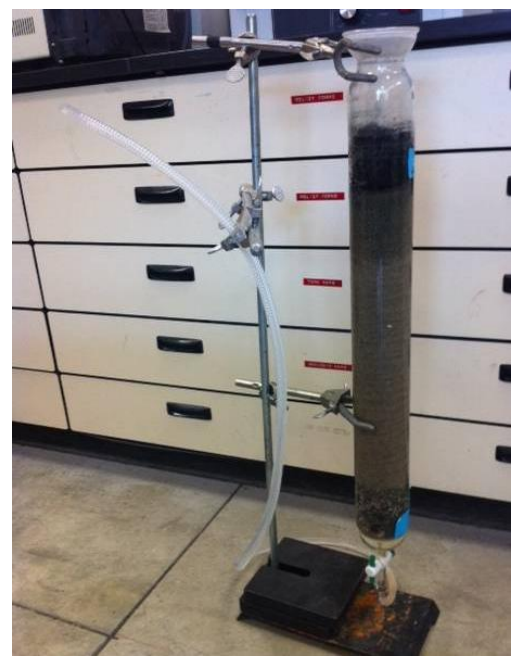

C)

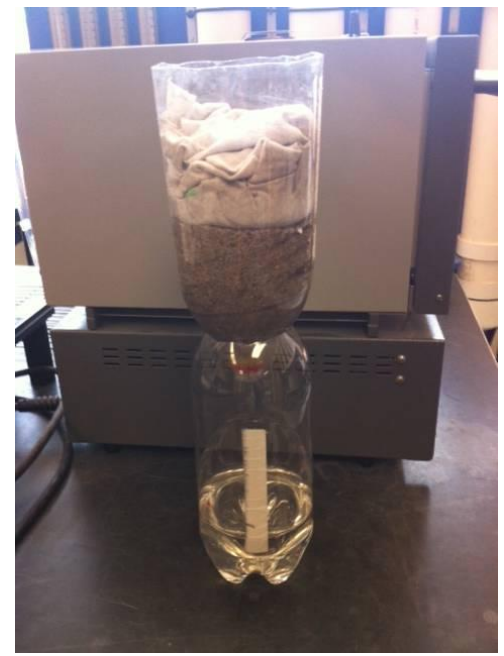

FIGURE 4

A) CAWST BIO-SAND FILTER DESIGN ${ }^{28}$

B) LABORATORY BIO-SAND FILTER WITH ACTIVATED CARBON LAYER 


\section{C) Stand-Alone Activated Carbon Treatment Option Using Plastic Bottle}

\section{CONCLUSIONS AND RECOMMENDATIONS}

As the demand for inexpensive agricultural products continues to increase along with the growing global population, the use of pesticides, herbicides, and fertilizers to increase the productivity of agricultural lands has also increased. In the developing world, where regulations are not strictly enforced, impoverished communities near these agricultural activities have suffered from pesticide, herbicide, and fertilizer-based contaminants leaching into their water supplies. POU water treatment applications have given many regions the opportunity and ability to treat their drinking water and reduce the health-related issues caused by biological and physical contaminants in their raw water sources. However, dissolved organic chemical contaminants will often pass right through the common POU treatment options currently available. Through our testing in Bluefields, it was shown that chemical contaminants produced from pesticide and herbicide-laden runoff could be potentially removed using activated carbon. The production of activated carbon could be adapted to almost any environment by using local agricultural waste byproducts and $\mathrm{NaCl}$, an inexpensive and accessible chemical. Lastly, we determined that this treatment system could be coupled with the existing water filtration system to act as a dual media filter to provide the greatest degree of treatment.

Further testing prior to future field-scale use of the $\mathrm{NaCl}$-activated carbon is recommended to extend our observations and conclusions to other contaminants. In addition, testing for other available agricultural waste byproducts as a raw carbon source for activated carbon production should be investigated as coconut shells will not be available in all locations. Lastly, as polluted waters may contain multiple organic impurities, field-testing these systems with actual source waters should be conducted to characterize the level of competition for available adsorption sites on the carbon and its effect on the operating life of the material.

Input received from the local population where these upgraded water treatment systems eventually will be implemented was a critical step in identifying appropriate long-term application technologies. The site visit was also instrumental in identifying the appropriate, available raw materials to be used. The use of a dye-based surrogate test material was also verified as both an effective means of quality control in the activated carbon production process and as a tool in educating the local population as to how this material can assist in improving the quality of their drinking water. The insights gained from visiting and communicating with the future users should allow for a more successful implementation of the upgraded systems and devices.

\section{ACKNOWLEDGMENTS}

We would like to acknowledge blueEnergy for their support and guidance during our experimentation in Bluefields and for facilitating our stay. We are also very grateful for the support of the School of Engineering at Santa Clara University for providing financial assistance related to our travel expenses and for the equipment used during the experimental phase of the project. Finally, we would like to thank the reviewers for their time and insightful comments to ensure the production of the best final product.

\section{REFERENCES}




\footnotetext{
${ }^{1}$ World Health Organization (WHO), 2000, Global water supply and sanitation assessment 2000 report, January 2004, v

${ }^{2}$ Gleick, Peter. "The Millennium Developement Goals for Water: Crucial Objectives, Inadequate Commitments." In The World's Water, 2004-2005: The Biennial Report on Freshwater Resources, Baltimore: Island Press (2004): 1 ${ }^{3}$ UNICEF and World Health Organization. "Meeting the Mdg Drinking Water and Sanitation Target: The Urban and Rural Challenge of the Decade." New York (2006), 7

${ }^{4}$ Ongley, Edwin. "Pesticides as Water Pollutants." In Control of Water Pollution from Agriculture. Rome: Food and Agriculture Organization of the United Nations, 1996.

${ }^{5}$ Gadgil, Ashok. "Drinking Water in Developing Countries." Annual Review of Energy and the Environment 23 (1998): 263

${ }^{6}$ Gadgil, "Drinking Water in Developing Countries," 257.

${ }^{7}$ Gadgil, "Drinking Water in Developing Countries,." 263.

${ }^{8}$ World Development Report: Agriculture for Development, World Bank 2008; http://

siteresources.worldbank.org/INTWDR2008/Resources/WDR_00_book.pdf (cited by MA Watts, 2009)

${ }^{9}$ Wilson, John, and Tsunehiro Otsuki. "To Spray or Not to Spray: Pesticides, Banana Exports, and Food Safety." Washington, D.C.: Development Research Group, World Bank, (2002), 5.

${ }^{10}$ Gadgil, "Drinking Water in Developing Countries.," 265.

${ }^{11}$ Sobsey, Mark, Christine Stauber, Lisa Casanova, Joseph Brown, and Mark Elliott. "Point of Use Household Drinking Water Filtration: A Practical, Effective Solution for Providing Sustained Access to Safe Drinking Water in the Developing World." Environmental Science \& Technology 42 (12) (2008): 4261.

12 Ramsey, Patrick. "Raas-Bluefields." http://www.amigosdenicaragua.org/bluefields.htm.

13 "Blueenergy." http://www.blueenergygroup.org.

${ }^{14}$ Maps of Bluefields." World Maps Maps and Flags of the World, http://www.justmaps.org.

${ }^{15}$ Martin, Robert. "Activated Carbon Product Selection for Water and Wastewater Treatment." Industrial \& Engineering Chemistry Product Research and Development 19, No. 3 (1980): 439.

16 "Fuel from the Fields: Charcoal from Agricultural Waste." edited by Massachusetts Institute of Technology: Practical Action, 2009.

${ }^{17}$ Wunder, Sven. "Deforestation and the Uses of Wood in the Ecuadorian Andes." Mountain Research and Development 16, No. 4 (1996): 367.

${ }^{18}$ Ahmadpour, A., and D. D. Do. "The Preparation of Activated Carbon from Macadamia Nutshell by Chemical Activation." Carbon 35, No. 12 (1997): 1723-32.

19 "Fuel from the Fields: Charcoal from Agricultural Waste." edited by Massachusetts Institute of Technology: Practical Action, 2009.

${ }^{20}$ AURO Carbon \& Chemicals. "Activated Carbon Powder."

http://www.indiamart.com/aurocarbonandchemicals/activated-carbon-powder.html.

${ }^{21}$ Water Professionals. "Activated Carbon Filters." http://www.waterprofessionals.com/process-

water/activated_carbon_filters.html.

${ }^{22}$ Sandhyarani, Ningthoujam. "How to Make Activated Charcoal." http://www.buzzle.com/articles/how-to-makeactivated-charcoal.html.

${ }^{23}$ U.S. Environmental Protection Agency. " Atrazine Updates. "

http://www.epa.gov/opp00001/reregistration/atrazine/atrazine_update.htm

${ }^{24}$ Hach $^{\mathrm{TM}}$ Company. "Pocket Colorimeter ${ }^{\mathrm{TM}}$ II Test Kit Immunoassay Instruction Manual." 19-28, 2006.

25 "Beer's Law." Sheffield Hallam University, http://teaching.shu.ac.uk/hwb/chemistry/tutorials/molspec/beers1.htm.

${ }^{26}$ Kosaka, H. and H. Kirota. 1991. Chemically activated shaped carbon, process for producing same and use thereof. US Patent 5,039,651, filed September 7, 1989, and issued August 13, 1991.

${ }^{27}$ Centre for Affordable Water and Sanitation Technology. "Biosand Filter." http://www.cawst.org/en/resources/biosand-filter.

${ }^{28}$ Centre for Affordable Water and Sanitation Technology. "Biosand Filter."
} 